\title{
Site-specific disease profiles in fish and their use in environmental monitoring
}

\author{
G. D. Stentiford*, J. P. Bignell, B. P. Lyons, S. W. Feist
}

Centre for Environment, Fisheries and Aquaculture Science (Cefas), Weymouth Laboratory, Weymouth, Dorset DT4 8UB, UK

\begin{abstract}
Clinical fish disease and liver pathology are high-level indicators of ecosystem health. Internationally agreed protocols for their measurement have allowed for the comparison of datasets that transcend international marine boundaries and have promoted the collection of quality assured data by several countries bordering the northeast Atlantic and associated seas. Here, grossly visible diseases and liver lesions (including tumours) were recorded between 2002 and 2006 from UK Clean Seas Environmental Monitoring Programme sites in the Irish and North Seas and in the English Channel. Diagnosis followed protocols developed by the International Council for the Exploration of the Sea and the Biological Effects Quality Assurance in Monitoring Programmes. Multivariate data analysis revealed a stable disease profile at most sites sampled. Sites with the highest levels of grossly visible diseases and liver lesions consistently grouped together within a given year, and distinctly from those sites displaying a lower prevalence of disease. Between-year analyses for these sites demonstrated the repetitive nature of these patterns, suggesting a relatively consistent disease profile between years, even at open ocean sites. Assessment of prevalence for the different diseases allowed for development of a grading system that assigned relative harm scores for populations existing at a particular site. Grading of harm scores into site types may provide an assessment tool for managers to identify sites of concern and to crosscorrelate disease with potential causal factors. The use of disease data in marine environment status monitoring is discussed.
\end{abstract}

KEY WORDS: Epidemiology · Grossly visible fish diseases · Histopathology · Liver pathology · Monitoring • Neoplasia · Quality assurance

Resale or republication not permitted without written consent of the publisher

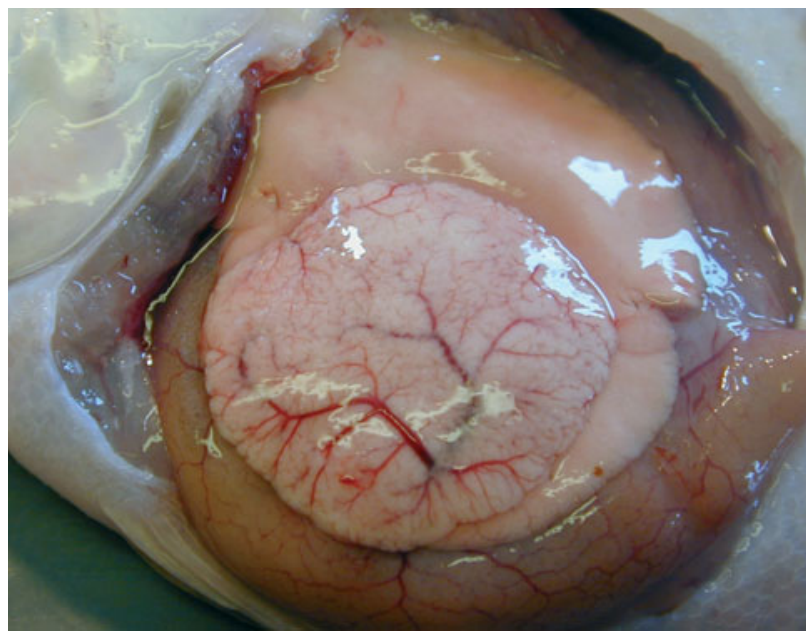

Liver tumours in Limanda limanda are recorded as part of the annual Clean Seas Environmental Monitoring Programme in the UK.

Photo: Grant Stentiford

\section{INTRODUCTION}

Several studies on marine epizootics in the past decade have led to the suggestion that the number and extent of disease outbreaks in marine organisms is increasing (reviewed by Lafferty et al. 2004). However, Ward \& Lafferty (2004) have stated that due to a lack of baseline data for disease in many species groups, demonstration of clear evidence for an increase in the number or extent of outbreaks is problematic. Although these studies highlight our relative lack of understanding of disease processes in even our most abundant marine species groups, they also provide published evidence that acute epizootics can generate 
mortalities extensive enough to create populationlevel effects in those species implicated. In addition to acute epizootics, significant interest also lies in the measurement of sublethal infections and non-infectious conditions (such as cancer or neoplasia, and lesions involved in the process of neoplasia) that provide an indicator for the general health status of a given population at a given point in time. In this context, fish diseases caused by pathogenic agents, and liver histopathology (including that associated with cancer), have been recorded in national marine and estuarine monitoring programmes for many years (Lang \& Dethlefsen 1996). Within the northeast Atlantic region, guidelines for biological effects of contaminants monitoring include the measurement of fish disease for general (non-specific) monitoring and of liver nodules (tumours) and liver histopathology for polycyclic aromatic hydrocarbon (PAH)-specific effects. As part of the UK Clean Seas Environmental Monitoring Programme (CSEMP), the disease status of the flatfish species dab Limanda limanda at offshore sites and flounder Platichthys flesus at inshore and estuarine sites are monitored according to the procedures of the Oslo and Paris Commission (OSPAR) Coordinated Environmental Monitoring Programme (CEMP) (OSPAR 1998a,b). Grossly visible diseases present in these sentinel species include lymphocystis, epidermal hyperplasia and papilloma, acute and healing ulcerations of the skin, and hyperpigmentation of the skin. Although the aetiology of these and other pathologies is not known in all cases, and may well be multifactorial in nature, taken together their measurement within populations provides a high-level indicator of health status amongst individuals comprising those populations. Such data have been used to detect long-term trends in disease prevalence at given locations and, in combination with other biomarkers of exposure, are used to provide greater confidence in the use of fish diseases as indicators of contaminant effects (Lang \& Dethlefsen 1996, Wosniok et al. 2000).

The presence of liver tumours (neoplasms) is also recorded routinely in dab and flounder populations sampled as part of CSEMP. In flatfish liver, the presence of neoplasia has been classified as a direct indicator of contaminant exposure and likely represents a biological endpoint of historic exposure to chemicals that initiate and promote carcinogenic pathways (Myers et al. 1990, 1991, 1992, 1994, Schiewe et al. 1991, Reichert et al. 1998). As a result, the presence of grossly visible and histologically confirmed liver neoplasms and other hepatic lesions involved in neoplasia has been used for many years in environmental monitoring programmes around the world (Myers et al. 1987, 1992, 1998, Stein et al. 1990, Vethaak \& Wester 1996, Stentiford et al. 2003, Lyons et al. 2004). At some offshore sites in the North Sea, liver tumour prevalence in wild flatfish has exceeded $10 \%$ in recent years (Feist et al. 2004, Cefas 2007), whereas prevalence in estuarine species can be significantly higher (Stentiford et al. 2003, Koehler 2004). These figures are significantly higher than those observed in other wildlife populations (e.g. Fowler 1987, Harshbarger 2004), indicating either a higher propensity for cancer in these species or a relatively higher exposure to carcinogens via the aquatic environment.

In addition to the assessment of grossly visible tumours, histopathological assessment of liver samples from flatfish populations collected under CSEMP allows for the diagnosis of microscopic lesions not visible during whole fish assessments. The lesions recorded by use of this approach include those thought to precede the development of benign and malignant lesions such as foci of cellular alteration, non-neoplastic toxicopathic lesions (such as nuclear and cellular polymorphism) and lesions associated with cell death, inflammation and regeneration. Currently, 32 categories of liver lesion are classified under the international Biological Effects Quality Assurance in Monitoring Programmes (BEQUALM) project. The diagnosis of these lesion types in the dab and flounder liver follows the guidelines set out by Feist et al. (2004). Similar guidelines exist for diagnosis of liver lesions in medaka Oryzias latipes (Boorman et al. 1997) and English sole Parophrys vetulus (Myers et al. 1987).

Systematically collected data on fish disease in wild populations is rare, and the majority of those datasets available are those collected during and following overt disease epizootics (Lafferty et al. 2004). Where monitoring programmes do track disease prevalence over space and time, it should be possible to make firm comments regarding whether prevalence is increasing or decreasing and where hotspots and reference sites exist. By use of such an approach, factors that coincide with these changes in disease prevalence (such as pollution, changes in population structure and climate change) may be implicated as causal, related or nonassociated. Since 2001, CSEMP data for clinical disease and liver pathology have been collected by use of quality assured procedures developed under BEQUALM. As such, datasets from 2002 until the present are directly comparable by use of high-level approaches such as those offered by multivariate statistics packages like PRIMER ${ }^{\mathrm{TM}}$. Through PRIMER ${ }^{\mathrm{TM}}$, we have analysed 3 major datasets pertaining to grossly visible disease and liver pathology in fish collected from 23 UK CSEMP sites in the North Sea, Irish Sea and English Channel visited annually from 2002 to 2006. By using such an approach, it is possible to discriminate particular sites ('site typing') based upon the diseases in fish captured at those sites. Furthermore, 
by comparing datasets collected at these individual sites over several years, it is possible to assess whether disease profiles are repeated or change significantly over time. To our knowledge, this is the first attempt to utilise a multivariate statistical approach to discriminate marine sites based upon multiple disease variables in resident fish populations. Data has been further processed to create a simple assessment criterion that defines the relative health of populations from particular sites. It should be noted that this analysis does not account for causality to the pattern observed and that features inherent in the host population at a given site, such as size, while controlled across groups, may not account for other features such as age. These aspects are considered in the discussion. The development of such assessment tools is timely with the UK Department for Environment, Food and Rural Affairs (Defra) Charting Progress Report (Defra 2005) and OSPAR Quality Status Reports 2010 (OSPAR 2000) looming alongside the introduction of the new European Union Marine Strategy Directive (MSD). Site typing of this kind provides environmental managers with assessment tools to identify regions of concern and to cross-correlate disease with potential causal factors associated with those locations.

\section{MATERIALS AND METHODS}

Dab Limanda limanda were captured at CSEMP sites (Fig. 1) during June and July 2002 to 2006 by use of 30 min tows of a standard Granton trawl. Upon landing, $50 \mathrm{dab}$ of 20 to $25 \mathrm{~cm}$ total length from each site in each year were immediately removed from the catch and placed into flow-through tanks containing aerated seawater (according to Feist et al. 2004). The sex, size (total length) and presence of grossly visible signs of disease were recorded for each fish using the methodology specified by the International Council for the Exploration of the Sea (ICES) (Bucke et al. 1996). Representative images of the grossly visible diseases are shown in Fig. 2. Following grossly visible disease assessment, fish were euthanised and, upon opening of the body cavity, the liver was assessed for the presence of visible tumours according to the guidelines set out by Feist et al. (2004). Liver samples were removed and fixed for $24 \mathrm{~h}$ in $10 \%$ neutral buffered formalin (NBF) before transfer to $70 \%$ industrial methylated spirit (IMS) for subsequent histological assessment. In order to prevent the appearance of post mortem artefacts, only live fish were sampled. Due to prevailing weather conditions, not all sites were visited in each year.

Histopathology. Fixed samples were embedded in wax in a vacuum infiltration processor by using standard protocols (Feist et al. 2004). Sections were cut at
3 to $5 \mu \mathrm{m}$ on a rotary microtome and resulting tissue sections mounted onto glass slides before staining with haematoxylin and eosin (H\&E). Stained sections were analysed by light microscopy (Eclipse E800, Nikon) and diagnosis of liver lesion type followed the guidelines set out by Feist et al. (2004) for flatfish liver. Digital images of histological features were obtained by use of the Lucia ${ }^{\mathrm{TM}}$ Screen Measurement System (Nikon). Representative images of normal liver and the 5 liver histopathology categories (NNT: non-neoplastic toxicopathic; NSI: non-specific inflammatory; FCA: foci of cellular alteration; BN: benign neoplasm; and MN: malignant neoplasm) are given in Fig. 3.

Data analysis. The percentage prevalence of macroscopically visible liver tumours in dab was calculated from the 50 fish collected at each CSEMP station. Histological samples of liver collected from the same fish were used to confirm neoplasia and to calculate the true (histological) prevalence of liver tumours in fish from these sites. The measurement of liver tumour prevalence in this way allows for an assessment of the effect of sampling method (macroscopic vs. microscopic assessment) on the accuracy of tumour prevalence data collected under CSEMP and other monitoring programmes.

Multivariate statistical analysis of grossly visible disease and liver histopathology data was carried out by use of the PRIMER ${ }^{\mathrm{TM}} 6.0$ software package (Clarke

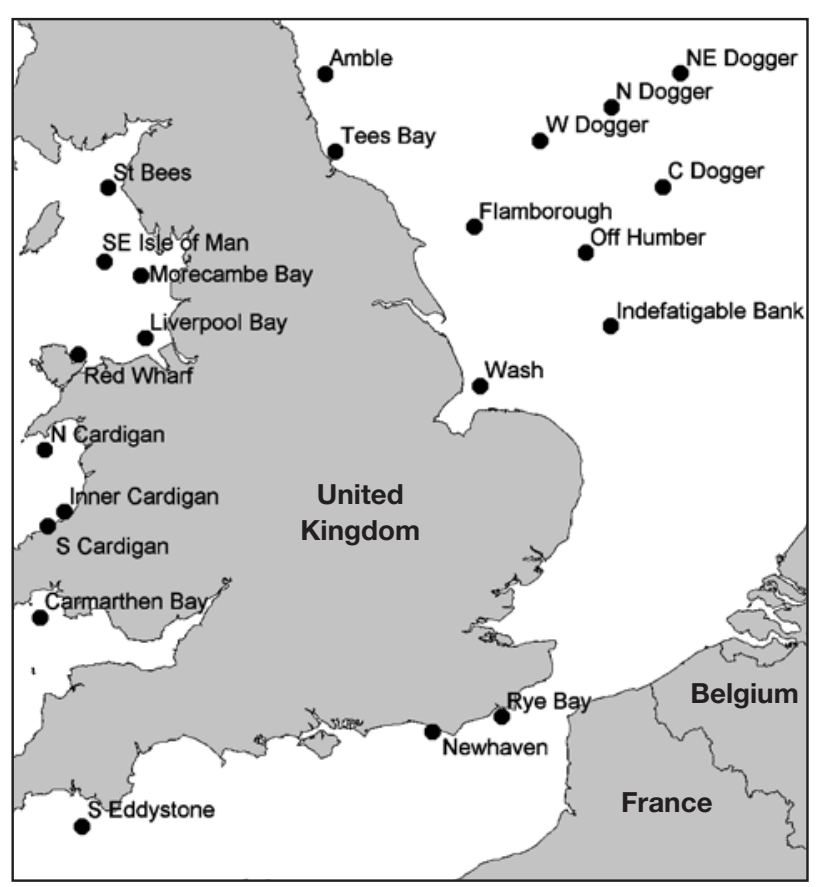

Fig. 1. UK Clean Seas Environmental Monitoring Program (CSEMP) sites sampled from 2002 to 2006. Fish disease data collected from these sites were used to generate disease prevalence ranges and quartiles for individual disease variables 

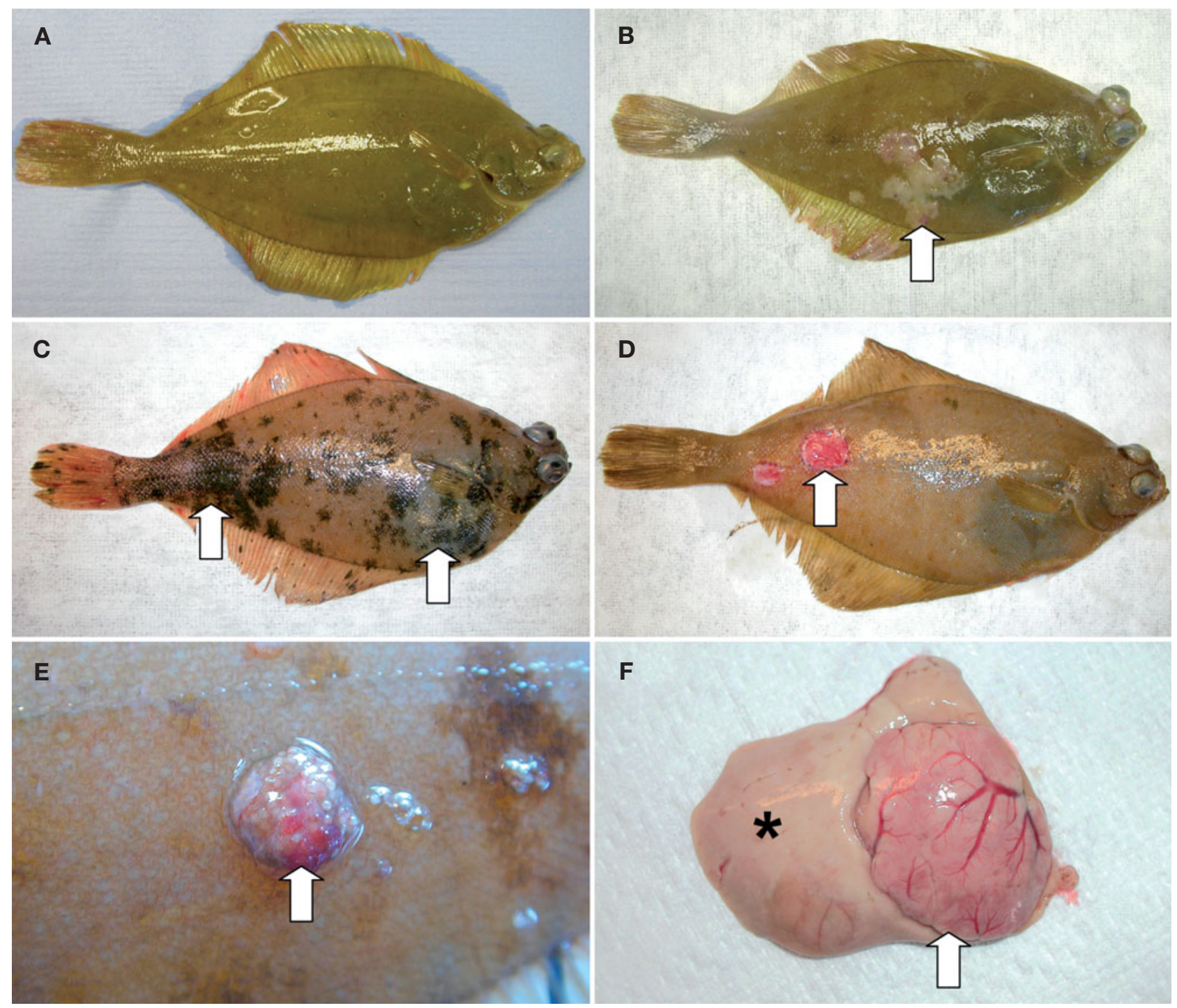

Fig. 2. Limanda limanda. Representative images of grossly visible diseases of dab according to ICES criteria (Bucke et al. 1996). (A) No visible external diseases. (B) Epidermal papilloma (EP) on skin (arrow). (C) Skin hyperpigmentation (HYP), multi-focal hyperpigmented regions on skin (arrows). (D) Skin ulceration (U) (arrow). (E) Lymphocystis (LY), cluster of infected subepidermal fibroblasts (arrow). (F) Single large liver nodule (LN) (arrow) and adjacent apparently normal liver $\left(^{*}\right.$ )

\& Warwick 2001) (Primer-E). The primary aim of the analysis was to compare the disease profile of dab populations captured from CSEMP stations over the survey period (2002 to 2006). The mean prevalence of the 5 grossly visible diseases (LY: lymphocystis; EP: epidermal papilloma; U: skin ulceration; HYP: skin hyperpigmentation; and LN: liver nodules visible dur- ing dissection) and the 5 liver histopathology categories formed the 10-variable dataset for each site in each year. Specifically, liver histopathology data were generated by allocating the 32 BEQUALM liver lesions to 1 of the 5 liver pathology categories (Table 1). A principal components analysis (PCA) was then carried out using the 10-variable data to identify the key

Fig. 3. Limanda limanda. Representative liver lesions and pathology categories according to Feist et al. (2004). (A) Normal liver; no abnormality detected (NAD). (B) Nuclear pleomorphism (white arrows); non-neoplastic toxicopathic lesion (NNT). (C) Granuloma (white arrow) and melanomacrophage centres (black arrow); non-specific inflammatory lesion (NSI). (D) Focus of cellular alteration (white arrow); foci of cellular alteration (FCA). (E) Hepatocellular adenoma (white arrow); benign neoplasm (BN). (F) Hepatocellular carcinoma with atypical cellular and nuclear profiles (white arrow); malignant neoplasm (MN). H\&E staining 


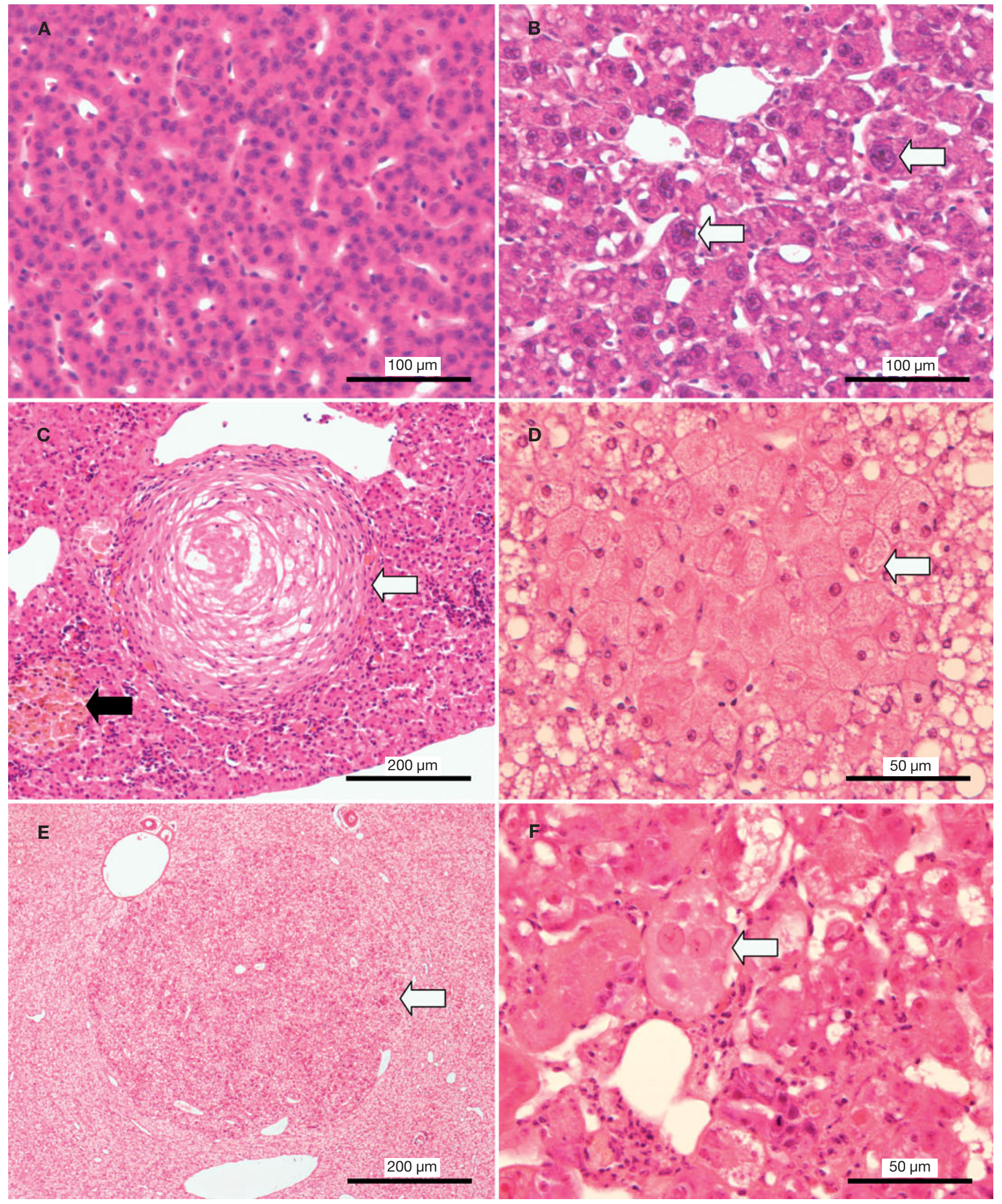


Table 1. Flatfish liver lesions and associated pathology categories as listed by BEQUALM (see Feist et al. 2004). The category 'No abnormality detected' is assigned to individual specimens that do not exhibit any of the pathologies listed in this table. Not all specific lesions were observed during the 2002-2006 sampling period

\begin{tabular}{|c|c|c|c|c|}
\hline $\begin{array}{l}\text { Non-specific and } \\
\text { inflammatory }\end{array}$ & $\begin{array}{l}\text { Non-neoplastic } \\
\text { toxicopathic }\end{array}$ & $\begin{array}{l}\text { Foci of cellular } \\
\text { alteration }\end{array}$ & Benign neoplasms & Malignant neoplasms \\
\hline $\begin{array}{c}\text { Coagulative necrosis } \\
\text { Apoptosis } \\
\text { Steatosis } \\
\text { Hemosiderosis } \\
\text { Variable glycogen } \\
\text { Melanomacrophages } \\
\text { Inflammation } \\
\text { Granuloma } \\
\text { Fibrosis } \\
\text { Regeneration }\end{array}$ & $\begin{array}{l}\text { Phospholipoidosis } \\
\text { Fibrillar inclusions } \\
\text { Polymorphism } \\
\text { Hydropic degeneration } \\
\text { Spongiosis hepatis }\end{array}$ & $\begin{array}{l}\text { Clear cell } \\
\text { Vacuolated } \\
\text { Eosinophilic } \\
\text { Basophilic } \\
\text { Mixed }\end{array}$ & $\begin{array}{c}\text { Hepatocellular adenoma } \\
\text { Cholangioma } \\
\text { Hemangioma } \\
\text { Pancreatic adenoma }\end{array}$ & $\begin{array}{c}\text { Hepatocellular carci- } \\
\text { noma } \\
\text { Cholangiocarcinoma } \\
\text { Pancreatic carcinoma } \\
\text { Hepatobiliary carcinoma } \\
\text { Hemangiosarcoma } \\
\text { Hemangiopericytic } \\
\text { sarcoma }\end{array}$ \\
\hline
\end{tabular}

drivers (amongst these variables) for site grouping or separation. A resemblance matrix was calculated based on a between-sites analysis and a non-metric multi-dimensional scaling (NMDS) plot was generated that incorporated data from all sites in all years. From the NMDS plots, individual bubble plots were produced to depict the prevalence of the individual diseases (grossly visible and liver pathology categories) at each of the sites based upon the pattern generated from NMDS.

Furthermore, statistical analysis of year-to-year changes in disease status at these sites was possible by comparing the 10-variable data from each survey year. To achieve this, we selected 9 common sites that were sampled in each survey year and applied the following analysis protocol to each year: PCA, resemblance matrices and NMDS plots were generated for each year followed by a comparison of annual disease profiles by use of the RELATE function in Primer ${ }^{\mathrm{TM}}$ 6.0. Rho (R) values and significance levels were recorded for each year-to-year comparison.

\section{RESULTS}

Grossly visible diseases and lesions of the liver of dab captured at the CSEMP stations between 2002 and 2006 were typical of those described previously by Bucke et al. (1996) and Feist et al. (2004) for European flatfish species. In total, disease status was assessed in 4450 fish collected from 89 sites between 2002 and 2006. The prevalence of each grossly visible disease and liver pathology category at each site in each year is summarised in Appendix 1, Table A1 (available as supplementary material at www.int-res.com/articles/ suppl/m381p001_app.pdf). Data presented in this table formed the multi-year, multivariate dataset analysed by use of Primer ${ }^{\mathrm{TM}} 6.0$.

\section{Comparison of macroscopic and microscopic nodule data}

The prevalence of macroscopically visible liver nodules recorded in the field was compared to histopathological data from the same specimens. By comparing prevalence by use of both techniques, it was possible to generate a correction factor that may be applied in instances where only one technique is used. Taking all years together, macroscopic diagnosis underestimated the prevalence of neoplastic liver lesions by up to $8.4 \%$. The correction factor was highest for those sites where macroscopic tumour prevalence was highest (8.4, 8.3 and $7.3 \%$ for North Dogger, Inner Cardigan and North East Dogger, respectively) and lowest at those sites where macroscopic tumour prevalence was lowest ( $0 \%$ for Rye Bay, Carmarthen Bay, South Eddystone and Newhaven). A negative mean correction factor $(-0.5 \%)$ at Tees Bay demonstrated that, in some cases, macroscopic diagnosis of liver tumour nodules may overestimate their true microscopic prevalence. In these instances, macroscopically visible liver tumours were confirmed as inflammatory or cystic in nature rather than neoplastic by use of histopathology. By combining data from all sites in all years a mean correction factor of $3.2 \%$ was calculated.

\section{Multivariate assessment of data (2002 to 2006)}

A 2-dimensional PCA ordination plot for the 10-variable combined year data is given in Fig. 4. Using the variable vector as a guide, sites discriminated in an approximately linear manner along the first principal component (PC1). As such, PC1 represented 55\% of the variability within the data. The second principle component (PC2) contributed a further $18.9 \%$ of the total variability (cumulative variability of PC1 + PC2 = 


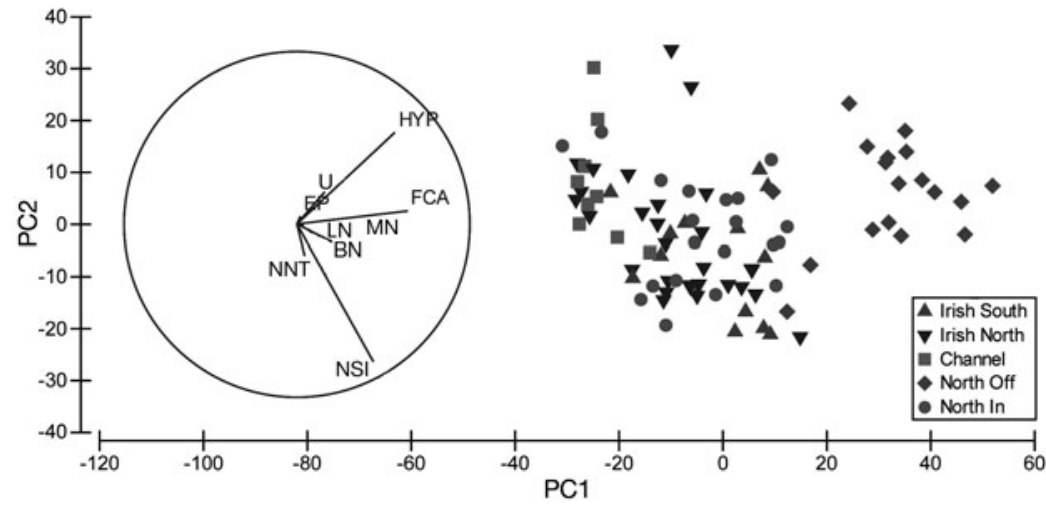

Fig. 4. Limanda limanda. Principal component analysis (PCA) of prevalence of 10 disease variables in dab from UK marine sites with 2 principal components plotted (PC1 and PC2). Variable vector in circle on left of plot. Grossly visible diseases and pathology categories as in Figs. 2 \& 3 separate bubble (prevalence) plots for the 10 disease variables, it was possible to visualise the drivers for the pattern. Figs. $6 \& 7$ represent 6 of the variables from the 10variable dataset. Sites in the upper left quadrant (e.g. ND, WD, NED) were classified by relatively higher prevalences of FCA, BN and MN, and by higher prevalences of grossly visible diseases, particularly HYP. Sites towards the lower right quadrant (e.g. RB, NH, RW, CB) were classified by relatively lower levels of FCA, benign and malignant neoplasms, and grossly visible diseases. Overall, fish populations from sites in the upper left quadrant exhibited a higher prevalence of grossly visible diseases and liver lesions, particularly those associated with the carcinogenic $74 \%)$. Addition of a third, fourth and fifth principle component (PC3, PC4 and PC5; not shown in Fig. 4) fulfilled a cumulative variability of $95 \%$. Considering the eigenvector output data from Primer ${ }^{\mathrm{TM}}$, as a component of this variability, the prevalence of liver FCAs contributed most significantly to the distribution of sites along the PC1 axis. Sites in the negative aspect of PC2 were most significantly classified by the prevalence of liver inflammation, wherease sites in the positive aspect of PC2 were classified by prevalence of skin hyperpigmentation.

Following PCA, subsequent analysis of the 10-variable combined year data was carried out using NMDS (Fig. 5). For ease of interpretation, sites were geographically classified according to 5 categories: Irish Sea South, Irish Sea North, English Channel, Offshore North Sea (Dogger) and Inshore North Sea. By use of this approach, it was possible to visualise the discriminatory pattern of sites depicted in the PCA analysis (Fig. 4) and to further investigate similarities between sites based upon the individual components (diseases) that comprised the pattern. Once again, the NMDS depicted a clear separation of sites along a fairly linear plane. Sites such as West Dogger (WD), North Dogger (ND) and North East Dogger (NED) clustered towards the upper left quadrant of the plot, whereas Rye Bay (RB), Newhaven (NH), Red Wharf (RW) and Carmarthen Bay (CB) clustered towards the bottom right quadrant of the plot. Liverpool Bay (LB), Inner Cardigan (IC), Off Humber (OH), Flamborough (FL), Morecambe Bay (MB) and Burbo Bight (BB) occupied the space between these extremes (Fig. 5). By representing the NMDS plot as

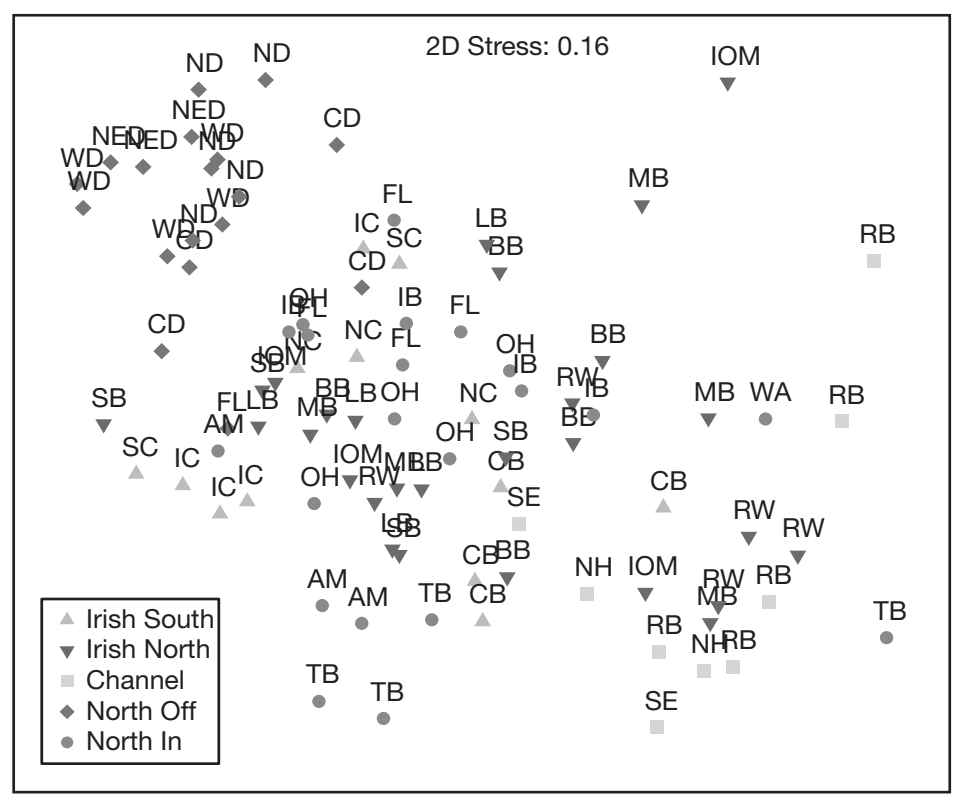

Fig. 5. Limanda limanda. Non-metric multi-dimensional scaling (NMDS) plot of disease prevalence data from dab from UK marine sites. Sites are classified into broad regional groups (see key). Sites in the upper left quadrant are principally those from the offshore North Sea while those in the lower right quadrant are principally Channel sites. Sites from the Irish Sea and Inner North Sea dominate the centre of the plot. See Table A1 (www.int-res.com/articles/suppl/m381p001_app.pdf) for site codes 

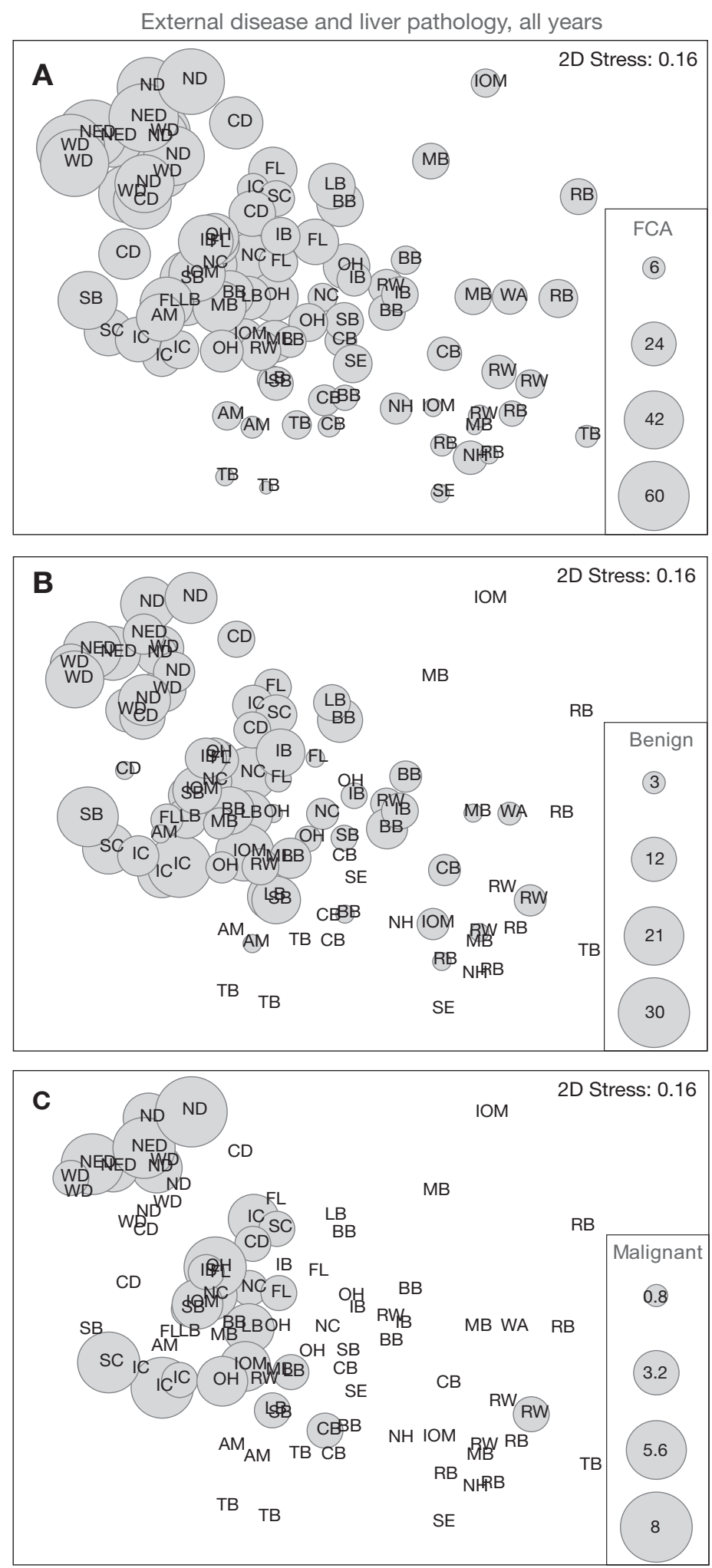

Fig. 6. Limanda limanda. Bubble plots for specific disease variables contributing to the NMDS plot shown in Fig. 5. (A) Liver foci of cellular alteration (FCA). (B) Benign liver neoplasm. (C) Malignant liver neoplasm. Bubble size depicts the prevalence (\%) according to the specific key associated with each panel. See Table A1 for site codes the sites RB, RW and $\mathrm{NH}$, amongst others), with only approximately $70 \%$ similarity to all other sites from all years, was also formed. A final broad cluster within the middle of the plot separates from the other 2 major clusters at a similarity level of approximately $76 \%$ (data not shown). This final cluster contained the sites that existed within the centre of the NMDS (Fig. 5) and bubble (Figs. 6 \& 7) plots: LB, IC, OH, FL and BB.

In summary, PCA, NMDS and cluster analysis of all data from all years demonstrated discrimination of sites based upon the prevalence profile of grossly visible disease and liver lesions found at those sites. Sites on the Dogger Bank appeared to form a discrete grouping away from those in the Inner North Sea, English Channel, and Irish Sea based upon the co-occurrence of relatively higher prevalence of liver lesions involved with the stepwise process of liver neoplasia, and those representing skin hyperpigmentation. Sites in the English Channel and some Irish Sea and Inner North Sea sites (e.g. $\mathrm{CB}, \mathrm{RW}$ and $\mathrm{TB}$ ) were defined by their relatively low levels of grossly visible disease and liver pathology. Remaining sites in the Irish Sea and Inner North Sea were intermediate between these extremes.

\section{Year-to-year comparisons}

To test the reproducibility of using grossly visible disease and liver pathology data as an efficient site discriminator, a year-to-year comparison of Primer ${ }^{\mathrm{TM}}$ resemblance matrices was carried out using data from 9 sites commonly visited in each of the 2002 through 2006 sampling campaigns: $\mathrm{BB}, \mathrm{FL}, \mathrm{LB}, \mathrm{MB}, \mathrm{ND}, \mathrm{OH}, \mathrm{RW}$, $\mathrm{RB}$ and WD. Year-to-year comparisons were made by utilising the RELATE function within Primer ${ }^{\mathrm{TM}}$. This utilised a Spearman rank correlation to test the null hypothesis of no relation between 2 datasets (e.g. 2002 vs. 2003 data), a Rho value of 1 suggesting perfect correlation between 2 resemblance matrices and a value of 0 suggesting no relationship between matrices. A comparison matrix for the 10 -variable data from 9 sites over 5 yr (2002 to 2006) is given in Table 2. Year-to-year comparisons yielded Rho values ranging from 0.386 and 0.74 , with a mean year-to-year value of 0.601 . These test statistics suggest that NMDS plots generated for each sampling year using the common 10 disease variables show a significant degree of similarity. Furthermore, datasets that are separated by 
External disease and liver pathology, all years
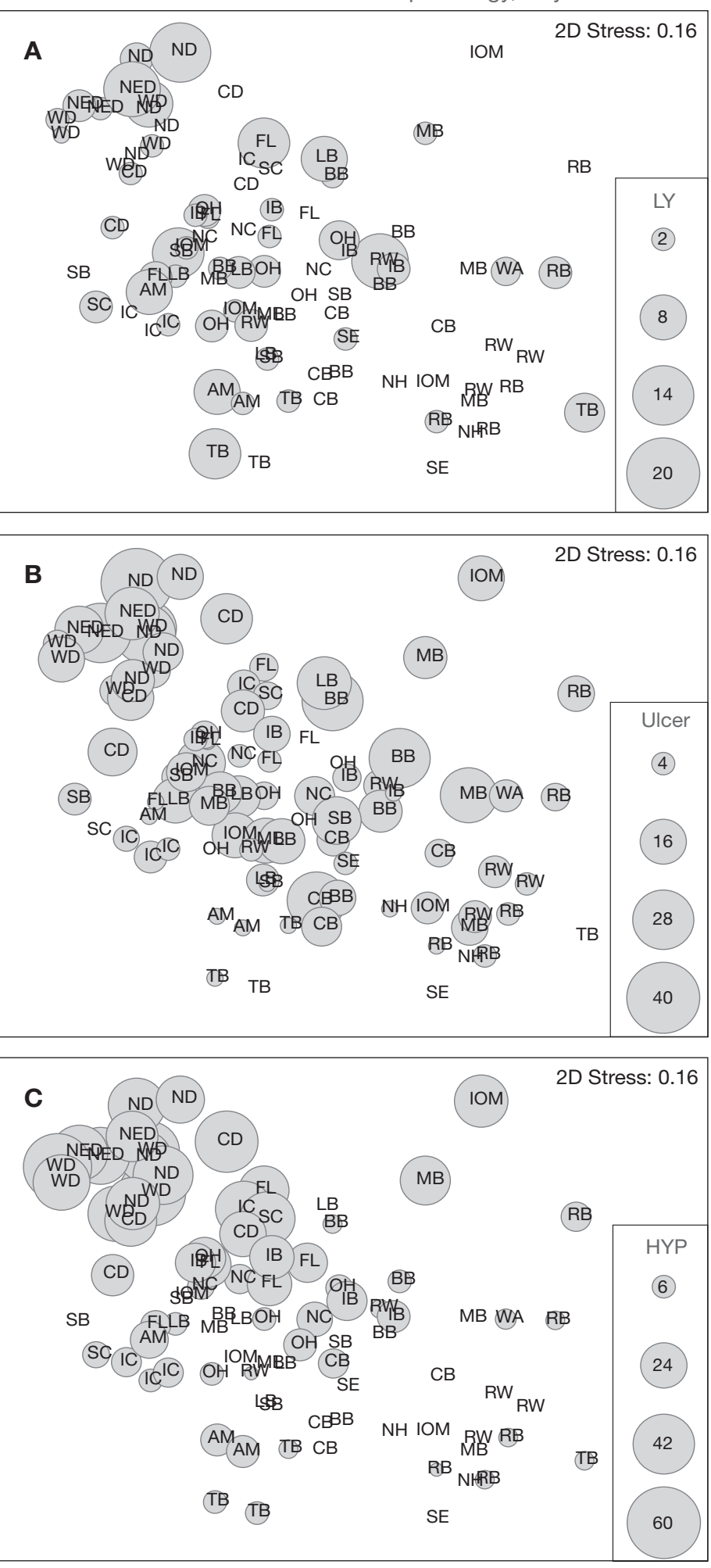

Fig. 7. Limanda limanda. Bubble plots of specific disease variables contributing to the NMDS plot in Fig. 5. (A) Lymphocystis infection (LY). (B) Skin ulceration. (C) Skin hyperpigmentation (HYP). Bubble size depicts the prevalence (\%) according to the specific key associated with each panel. See Table A1 for site codes more than one year (e.g. 2002 vs. 2006) also showed a significant similarity $(\mathrm{R}=0.74, \mathrm{p}=$ 0.01). Deviations from perfect match (Rho value $=$ 1) are likely due to prevalence shifts in individual disease categories at given sites within each year (see Table A1). These patterns may be further investigated using dedicated trend analyses for these sites (not carried out in the present study). However, the Rho values presented in Table 2 allow rejection of the null hypothesis of no similarity between sampling years.

\section{Site type classification}

Table 3 lists the prevalence ranges for the 10 disease variables over the 5 yr period of the present study. By dividing the range of each disease variable into quartiles and assigning a score of 0 , 1, 2 and 3 to the baseline, lower-mid, mid-high and higher quartiles, respectively, it was possible to generate a simple grading system for each disease variable. Further, by applying this grading system to each disease variable at each site in each year of the present study, it was possible to generate a harm score for each site. Theoretical disease scores range from 0 (baseline quartile prevalence for all 10 disease variables) to 30 (higher quartile prevalence for all 10 disease variables). Disease scores for each site in each year are given in Table A1. The lowest disease scores were observed at Wash (WA, 0), RW (0), $\mathrm{RB}$ (1), South Eddystone (SE, 1) and NH (2), whereas the highest scores were observed at the Dogger Bank sites ND (17), WD (18) and NED (19). By expressing disease scores as a bubble plot overlay on the NMDS plot for the 10 disease variables from all sites and all years (Fig. 5) it was possible to show a gradation from low scores at sites in the lower right quartile of the plot (e.g. $\mathrm{RB}, \mathrm{NH}, \mathrm{RW}, \mathrm{CB})$ to the highest scores at sites in the upper left quartile (predominantly ND, NED, WD and CD) (Fig. 8). Separation of the 5 grossly visible disease category scores from the 5 liver pathology category scores allowed the harm score to be represented as a combined score for grossly visible disease and liver pathology (both of which range from 0 to 15). An arbitrary division of these 2 harm scores into 3 categories $(<5$, $>5$ and $<10$, and $>10$ ) defined a broad classification system of site types (A, B and C) according to the grossly visible disease and liver pathology profiles of flatfish found at those sites. The simple site classification system is provided in Table 4 . Separation of the grossly visible disease score 
Table 2. Limanda limanda. RELATE scores for year-to-year comparisons of dab disease profile resemblance matrices using PRIMERT 6.0 . R-values of 1 depict $100 \%$ similarity in fish disease profiles between years, while values of 0 depict no similarity in disease profiles between years

\begin{tabular}{|cccccc|}
\hline & 2002 & 2003 & 2004 & 2005 & 2006 \\
\hline 2002 & & & & \\
2003 & $R=0.515$ & & & \\
& $(p=0.01)$ & & & \\
2004 & $R=0.567$ & $R=0.603$ & & \\
& $(p=0.01)$ & $(p=0.01)$ & & \\
2005 & $R=0.39$ & $R=0.614$ & $R=0.669$ & \\
& $(p<0.05)$ & $(p<0.05)$ & $(p<0.05)$ & \\
2006 & $R=0.74$ & $R=0.506$ & $R=0.386$ & $R=0.423$ \\
& $(p=0.01)$ & $(p<0.05)$ & $(p<0.05)$ & $(p<0.05)$ \\
\hline
\end{tabular}

from the liver pathology score allowed the assessment to be applied even in scenarios where only one dataset (e.g. grossly visible disease) was available.

\section{DISCUSSION}

\section{Temporal and spatial stability in marine disease profiles}

In an attempt to classify the health status of the marine environment and, in particular, to associate observed effects with causal or potentially causal factors, an increasing number of so-called biological effects techniques have emerged in recent years. These include the measurement of physiological or metabolic biomarkers that are induced via exposure to chemical contaminants (exposure markers), or bio- assays that utilise endpoints such as reproductive status, growth, death, or disease in reference and impacted populations (endpoint markers) (Thain et al. 2008). For biological effects techniques to be useful in national or even international monitoring programmes, a demonstrable quality assurance protocol is required that allows users in different regions to apply the technique according to the agreed principles. Such approaches allow any data obtained to be reliably compared. For this reason, well-controlled approaches to marine monitoring activities such as those laid down in OSPAR CEMP are highly regarded as cornerstones that allow for marine environment status to be reliably assessed. OSPAR and the Helsinki Commission (HELCOM) have agreed on an ecosystem-based approach to monitoring and assessing the marine environment which attempts to understand interactions between human activities (e.g. pollution) and the effects that these activities have on resident biota (Thain et al. 2008). Currently, grossly visible fish diseases and the presence of liver nodules (including neoplasia) and liver pathology are recognised in the OSPAR Joint Assessment and Monitoring Programme and are afforded Category I status (i.e. a method suitable for marine monitoring purposes with analytical quality control established). At present, the analytical quality control for both grossly visible diseases and liver pathology are provided by a specific section of the European BEQUALM, a scheme in which participants partake in proficiency testing and ring trials prior to submission of their datasets to marine data stewards such as ICES. It is the goal of various ICES groups such as the Working Group for the Biological Effects of Contaminants and the Working Group on Pathology and Diseases of Marine Organisms (WGPDMO) to review the status of biological effects techniques (such as disease and liver

Table 3. Limanda limanda. Prevalence ranges for 10 disease variables measured over the 5 yr study period. The prevalence range of each disease over the period has been divided into quartiles and a score has been assigned to each quartile (0 to 3 ). A zero score is taken to represent the $5 \mathrm{yr}$ baseline prevalence for each disease. Higher scores depict higher prevalences. Scores assigned to the prevalence of each disease at each site in each year allow an overall harm score to be assigned. Pathology category abbreviations as in Table A1

\begin{tabular}{|c|c|c|c|c|c|c|c|}
\hline & $\begin{array}{c}\text { Lowest } \\
\text { prevalence }\end{array}$ & $\begin{array}{c}\text { Highest } \\
\text { prevalence }\end{array}$ & Range & Baseline & Low-Mid & High-Mid & High \\
\hline NNT & 0 & 26 & 26 & 0 to 6.5 & 6.6 to 13 & 13.1 to 19.5 & $>19.5$ \\
\hline FCA & 2 & 58 & 56 & 0 to 16 & 16.1 to 30 & 30.1 to 44 & $>44$ \\
\hline $\mathrm{BN}$ & 0 & 24 & 24 & 0 to 6 & 6.1 to 12 & 12.1 to 18 & $>18$ \\
\hline $\mathrm{MN}$ & 0 & 8 & 8 & 0 to 2 & 2.1 to 4 & 4.1 to 6 & $>6$ \\
\hline NSI & 42 & 100 & 58 & 0 to 56.5 & 56.6 to 71 & 71.1 to 85.5 & $>85.5$ \\
\hline LY & 0 & 14 & 14 & 0 to 3.5 & 3.6 to 7 & 7.1 to 10.5 & $>10.5$ \\
\hline $\mathrm{U}$ & 0 & 38 & 38 & 0 to 9.5 & 9.6 to 19 & 19.1 to 28.5 & $>28.5$ \\
\hline EP & 0 & 14 & 14 & 0 to 3.5 & 3.6 to 7 & 7.1 to 10.5 & $>10.5$ \\
\hline HYP & 0 & 52 & 52 & 0 to 13 & 13.1 to 26 & 26.1 to 39 & $>39$ \\
\hline \multirow[t]{2}{*}{ LN } & 0 & 18 & 18 & 0 to 4.5 & 4.6 to 9 & 9.1 to 13.5 & $>13.5$ \\
\hline & & & Harm score & 0 & 1 & 2 & 3 \\
\hline
\end{tabular}


Table 4. Limanda limanda. Simple marine site classification scheme based upon disease profiles and derived harm scores in populations of dab captured at those sites. Free text provides a broad outline of the likely disease profile within each site type. Pathology category abbreviations as in Table A1

\begin{tabular}{|c|c|c|}
\hline Type A & Type B & Type C \\
\hline $\begin{array}{l}\text { Generally low prevalence }(<10 \%) \text { of } \\
\text { ICES external diseases and almost } \\
\text { complete absence of HYP }\end{array}$ & $\begin{array}{c}\text { Appearance of higher prevalence of } \\
\text { ICES external diseases (including LY, } \\
\text { U and HYP) }\end{array}$ & $\begin{array}{l}\text { Highest levels of ICES external diseases } \\
\text { (including up to } 50 \% \text { prevalence of HYP }\end{array}$ \\
\hline $\begin{array}{l}\text { Up to } 50 \% \text { of fish with no indication } \\
\text { of BEQUALM liver pathology }\end{array}$ & $\begin{array}{l}\text { Less than } 30 \% \text { of fish with no indication } \\
\text { of BEQUALM liver pathology categories }\end{array}$ & $\begin{array}{l}\text { Less than } 20 \% \text { of fish with no indication of } \\
\text { BEQUALM liver pathology categories (NAD) }\end{array}$ \\
\hline categories (NAD) & $(\mathrm{NAD})$ & $\begin{array}{l}\text { Similar prevalence of NNT liver lesions to } \\
\text { Type B sites but a consistently high preva- }\end{array}$ \\
\hline Low prevalence $(<5 \%)$ of fish with & Low prevalence $(<10 \%)$ of fish with NNT & lence (up to $100 \%$ ) of NSI liver lesions \\
\hline NNT liver lesions and approximately & liver lesions but an elevated prevalence & \\
\hline $50 \%$ prevalence of NSI liver lesions & of NSI liver lesions (up to $90 \%$ ) & $\begin{array}{l}\text { High prevalence (up to } 50 \% \text { ) of FCA with } \\
\text { BN liver tumour prevalence often exceeding }\end{array}$ \\
\hline Low prevalence of fish with liver & Prevalence of FCA can exceed $15 \%$. & $15 \%$. MN liver tumours still comparatively \\
\hline FCA $(<10 \%)$ and BN liver tumours & BN liver tumour prevalence around & rare though generally comprise a larger \\
\hline $\begin{array}{l}(<5 \%) \text {. MN liver tumours very rare } \\
\text { or absent }\end{array}$ & $\begin{array}{l}10 \% . \text { MN liver tumours more common } \\
\text { than in Type A (up to } 6 \% \text { ) }\end{array}$ & $\begin{array}{c}\text { proportion of observed liver tumours than } \\
\text { Type B (up to } 8 \% \text { ) }\end{array}$ \\
\hline $\begin{array}{l}\text { Liver pathology score }<5 \text { and/or } \\
\text { external disease score }<5\end{array}$ & $\begin{array}{l}\text { Liver pathology score }>5 \text { and }<10 \text { and/or } \\
\text { external disease score }>5<10\end{array}$ & $\begin{array}{c}\text { Liver pathology score }>10 \text { and/or external } \\
\text { disease score }>10\end{array}$ \\
\hline
\end{tabular}

pathology) and to provide organisations such as OSPAR and HELCOM with information pertinent to their usage (Thain et al. 2008).

The present study has reported on the application of these principles to monitoring of the UK marine environment under CSEMP. Grossly visible diseases and liver lesions were recorded from the sentinel flatfish

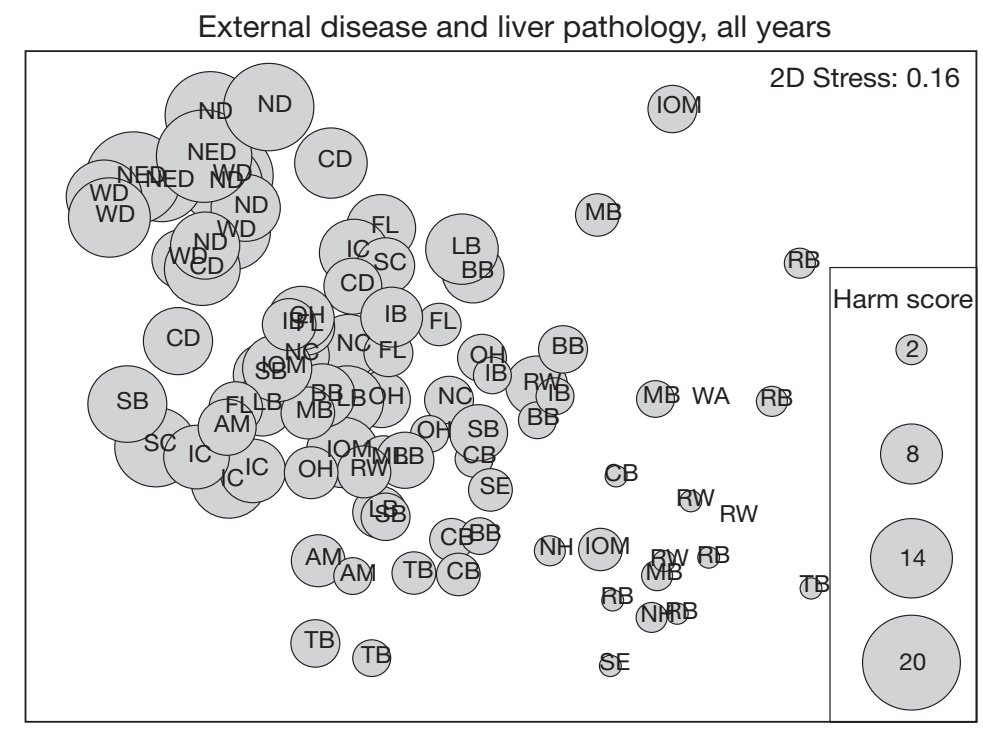

Fig. 8. Limanda limanda. Bubble plot of harm scores derived from assigning derived scores (Table 4) to disease prevalence data (Table 2). Harm scores are superimposed onto the NMDS plot (Fig. 5) of all disease data from all sites in all years. Highest harm scores are seen in the upper left quartile while lowest scores occur in the bottom right quartile (see scale). Bubble size in the legend depicts the harm score scale associated with the plot. See Table A1 for site codes species dab Limanda limanda by use of quality assurance principles laid down by ICES (Bucke et al. 1996, Feist et al. 2004). In addition to providing an overview of disease status in this species from a range of coastal and offshore sites in UK waters, the present study has demonstrated that the patterns of disease observed at these sites are largely stable over time and that certain sites and regions contain populations affected by significantly different disease profiles with differing prevalence.

Demonstration of stable geographical profiles is the first step in assessing the applicability of disease as a reliable marker of population health. As such, it allows sites to be discriminated based upon the relative harm caused by disease to populations residing therein, and further provides confidence in the diagnostic approach used to assess this harm. Secondly, relative temporal stability in harm scores generated from disease profiles demonstrates consistency in geographical patterns between years, thereby suggesting that this profile has an underlying basis, the cause of which can be further investigated. In the context of marine monitoring, such investigations may include measurements of inherent biological features in the populations of concern (e.g. age, diet, migrations and population genetics), known or unknown abiotic factors (e.g. temperature and salinity) or anthropogenic factors (e.g. chemical pollution and fishing pressure). 


\section{Disease: a biomarker or phenotypic anchor?}

Since one goal of multifactorial marine monitoring is to associate observed changes from a baseline situation with potential causes (e.g. the expression of biomarkers in sentinel species following their exposure to xenobiotics), it is important to consider which endpoints have the potential to demonstrate this accurately and which factors may complicate interpretation of data collected in the field. Diseases of the liver, in particular neoplastic and preneoplastic lesions of the liver of flatfish, have been widely employed as indicators of exposure to hydrocarbons and other chemicals in laboratory and field studies (e.g. Myers et al. 1991, 1998, Vethaak et al. 1996). As such, their presence at elevated levels at particular inshore or estuarine sites has been correlated with the burden of specific xenobiotic chemicals in the sediment and in tissues of fish from those sites (Koehler 1990, Stein et al. 1990, Myers et al. 2008). Although intuitive that the higher prevalence of liver neoplasia in dab from certain CSEMP sites identified in the present study may be associated with elevated levels of carcinogenic contaminants in sediment and tissues at those sites, or even elevated biomarker responses, the demonstration of these relationships has proved more elusive, with less clear links between causal contaminants and disease at offshore locations (Cefas 2006, 2007, Lyons et al. 2006). Work in our laboratory at present is attempting to interpret this apparent paradox by investigation of potential confounding factors that may alter the expression of biomarkers and the prevalence of disease. Whereas previous studies have described a single metapopulation of dab around the coast of the UK and in the North Sea (Rijnsdorp et al. 1992), we are now adopting a microsatellite marker-based approach to analyse populations of dab in the Irish Sea, English Channel and North Sea, to see if any significant degree of substructuring actually exists (Tysklind et al. in press). Whether such genetic distinctions between subpopulations of marine species could lead to differential susceptibility to diseases such as liver cancer is currently unknown. However, studies of this type highlight how ecological data will play an increasingly important role in interpretation of data collected for the purposes of assessing status of the marine environment. Effects of other confounding factors that may affect disease prevalence, such as the age, sex and migrational tendencies of sentinel species, have been amply highlighted by $\mathrm{Au}$ (2004). Studies to assess some of these factors are currently underway in our laboratory and are expected to describe at least a proportion of the variation observed between sites and regions. Recognising the contributing role of such factors will significantly refine our approaches to marine monitoring and will lead to a greater understanding of cause-effect pathways, particularly with respect to the biological effects of specific contaminant exposure.

Quantification and documentation of these life history parameters have been termed phenotype anchoring in recent studies that have attempted to align biomarker responses with higher-level health indicators (such as disease) in fish and molluscs (Stentiford et al. 2005, Ward et al. 2006, Hines et al. 2007, Bignell et al. 2008). By using this approach, the disease(s) per se may either be considered as a direct marker of environment status (e.g. liver cancer) or simply a variable associated with the host that may affect the measurement of a more specific biomarker. For this reason, in the context of marine monitoring, it may be pertinent to consider grossly visible diseases (generally nonspecific pathologies, parasites and microbial infections) separately from more specific pathologies (e.g. liver cancer and intersex) that have at least some demonstrable experimental link with exposure to, for instance, xenobiotic contaminants. This is recognised here by the separation of the grossly visible disease harm score from that generated from liver pathology data. In future studies, it is recommended that disease only be utilised as a biomarker if its induction has at least partially been demonstrated to be associated with exposure to a specific factor(s). Relevant examples may include liver cancer and pre-cancers, and gonadal pathologies such as intersex (Bateman et al. 2004, Stentiford \& Feist 2005). Other diseases, pathologies and conditions, such as those caused by parasites, microbial agents or unknown (idiopathic) factors, are nonetheless relevant to environmental monitoring programs, even though their cause may not be directly (or even indirectly) related to other data collected at a particular site. In these cases, rather than assessing these diseases as biomarkers per se, these observations become phenotypic data that act as additional cross-correlates (to sex, age, size, etc.) against which simultaneously collected data for chemistry or exposure markers can be assessed.

\section{Monitoring data and marine epidemiology}

Current epidemiological theory is largely based upon terrestrial systems and several recent reviews, while highlighting the potential significance of diseases in the marine environment, have suggested that qualitative differences within these environments introduce problems when attempting to apply terrestrial theories to marine pathogen dynamics. Such differences include the higher diversity in phylogeny and life history traits in marine organisms and, significantly, the open nature of marine environments that facilitates long 
distance dispersal of hosts and their pathogens (McCallum et al. 2004). These features lead to significantly higher dispersal rates of marine pathogens compared to terrestrial pathogens (McCallum et al. 2003) and create difficulties in applying standard spatial epidemiological approaches to this environment (Hess et al. 2001, Holt \& Boulinier 2005, Ostfeld et al. 2005). Although landscape epidemiology recognises the potential for biotic and abiotic factors to influence the spread of diseases in terrestrial populations, examples of similar scenarios in marine environments are less common. However, these principles have been discussed in relation to the prevalence of some marine pathogens. Specifically, an elevated prevalence of the dinoflagellate parasite Hematodinium sp. in marine decapods has been reported to be associated with specific features of the land-sea interface (e.g. embayments, lagoons and fjords; see Stentiford \& Shields 2005), whereas differential prevalence of nematodes has been observed in marine fish in the North Sea relative to temperature stratification of the water column (Klimpel \& Rückert 2005). Such examples highlight how diseases associated with either microbial or metazoan pathogens (such as the grossly visible diseases recorded in the present study) may be naturally variable in open ocean systems, but it may be possible to associate this natural variability with site-specific features if appropriate supporting metadata are available. Although interpreting the effect of the marine subsurface physical environment and other hydrographic features may seem immediately problematic in the context of marine epidemiology, the availability of electronic marine mapping and GIS opens the possibility for marine spatial epidemiology similar to that utilised in terrestrial systems. Open access datasets for marine diseases held by data stewards such as ICES could be utilised for such an approach. In this context, layering of disease maps with others for xenobiotic contaminants, biomarkers and other biotic and abiotic variables such as prevailing currents (Brown et al. 1999) may eventually provide the basis for a risk-based approach to monitoring the presence and spread of pathogens in marine environments. The availability of quality assured datasets for marine diseases of the type reported in the present study will undoubtedly assist the development of methodology for marine epidemiology and may also be useful in the context of disease risk analysis for future offshore aquaculture ventures.

\section{Classifying site types}

The repeatable patterns observed in fish disease profiles from sentinel flatfish collected at UK marine sites has allowed for the generation of a simple classi- fication system for the discrimination of site types that reflects the prevalence of those diseases in populations captured at the sites. Although site classifications inherently lead to a loss in resolution in empirical data associated with those locations, they are becoming an increasingly common assessment tool for judging the outcome of management intervention and to highlight sites or regions of highest concern. Furthermore, with continued development, fish disease status has a key role to play in determining Good Environmental Status as will be required under the European Union's Marine Strategy Directive. It is also vital that we continue to take an integrated approach when determining ecosystem health, with disease levels and biological effects tools adding value and providing complementary data to that provided by chemical and ecological methodologies (Hagger et al. 2006, Thain et al. 2006, 2008, Viarengo et al. 2007). In our opinion, site classification, based on either grossly visible diseases, liver lesions or both, provides a vital first step for the eventual integration of these high-level health data with biomarkers of exposure to contaminants and even with contaminant burdens in sediment, water or tissue. In addition, standardised classification of site types based upon the disease profile and prevalence enables assessment of long-term trends that may be associated with factors such as climate change (Harvell et al. 1999). For this purpose, WGPDMO have recently proposed a Fish Disease Index (FDI) that will be utilised for defining disease trends in fish captured from open ocean monitoring sites (ICES 2007). The introduction of the FDI represents the final phase in the development of robust quality assurance for the use of fish disease measurement and, coupled with the principles set out in the present study, will provide the first assessment tool for use by environmental managers to classify change (based on disease) in resident fish populations. Furthermore, it recognises the importance of disease as a high level indicator of health status in fish stocks.

\section{CONCLUSIONS}

Grossly visible disease and liver pathology data collected from sentinel flatfish by use of recognised quality assurance protocols can be utilised to discriminate geographically distinct marine sites in European waters. Disease profiles at given sites are largely stable between years, although the prevalence of individual diseases may vary temporally. Harm scores can be generated that depict the relative departure from a baseline health status in the fish population captured at a specific site. The components of the harm score derived from grossly visible disease data (generally 
considered non-specific) can be separated from those components derived from liver pathology data (including cancer). Separation allows for better resolution of potential cause-effect pathways (e.g. by comparison of specific disease data to other biotic and abiotic factors prevailing at a site). Harm scores and other features in the disease profile can be utilised to designate a specific site type that coincides with the profile and prevalence of grossly visible diseases and liver lesions measured at that site. Site typing provides a simple method to grade relative harm (due to disease) in populations residing at specific sites. Site typing and future departures from a specific site type may form the basis of an assessment tool for use by managers to assess reference and hotspot sites and to monitor the outcome of intervention strategies to improve marine environmental status.

Acknowledgements. The authors thank the crew of the RV 'Cefas Endeavour' for assistance with collection of samples and the staff of the Pathology and Epidemiology, and Environment and Animal Health teams at Cefas for assistance with field collection of data and preparation of tissues for histology. The authors also acknowledge the informed comments of 4 anonymous reviewers who collectively assisted with improving this manuscript. This work was supported by Defra under contract no. SLA24.

\section{LITERATURE CITED}

Au DWT (2004) The application of histo-cytopathological biomarkers in marine pollution monitoring: a review. Mar Pollut Bull 48:817-834

Bateman KS, Stentiford GD, Feist SW (2004) A ranking system for the evaluation of intersex condition in flounder (Platichthys flesus). Environ Toxicol Chem 23:2831-2836

Bignell JP, Dodge MJ, Feist SW, Lyons B and others (2008) Mussel histopathology: effects of season, disease and species. Aquat Biol 2:1-15

Boorman GA, Botts S, Bunton TE, Fournie JW and others (1997) Diagnostic criteria for degenerative, inflammatory, proliferative nonneoplastic and neoplastic liver lesions in medaka (Oryzias latipes): consensus of a national toxicology programme pathology working group. Toxicol Pathol 25:202-210

Brown J, Hill AE, Fernand L, Horsburgh KJ (1999) Observations of a seasonal jet-like circulation at the Central North Sea cold pool margin. Estuar Coast Shelf Sci 48:343-355

Bucke D, Vethaak AD, Lang T, Mellergaard S (1996) Common diseases and parasites of fish in the North Atlantic: training guide for identification. ICES Techniques in Marine Environmental Sciences 19, ICES, Copenhagen

Cefas (2006) Monitoring the quality of the marine environment, 2003-2004. Science series aquatic environment and monitoring report. Cefas Lowestoft 58, available at www. cefas.co.uk

Cefas (2007) Monitoring the quality of the marine environment, 2004-2005. Science series aquatic environment and monitoring report. Cefas Lowestoft 59, available at www. cefas.co.uk

Clarke KR, Warwick RM (2001) Change in marine communi- ties: an approach to statistical analysis and interpretation, 2nd edn. Primer-E, Plymouth

Defra (2005) Charting progress. An integrated assessment of the state of UK seas. Available at www.defra.gov.uk

Feist SW, Lang T, Stentiford GD, Koehler A (2004) Use of liver pathology of the European flatfish dab (Limanda limanda L.) and flounder (Platichthys flesus L.) for monitoring. ICES Techniques in Marine Environmental Sciences 38, ICES, Copenhagen

Fowler ME (1987) Zoo animals and wildlife. In: Theilen GH, Madewell BR (eds) Veterinary cancer medicine. Lea \& Febiger, Philadelphia, PA, p 649-662

Hagger JA, Jones MB, Leonard PDR, Owen R, Galloway TS (2006) Biomarkers and integrated environmental risk assessment: Are there more questions than answers? Integr Environ Assess Manag 2:312-329

Harshbarger JC (2004) Chronology of oncolygy in fish, amphibians and invertebrates. Bull Eur Assoc Fish Pathol 24:62-81

> Harvell CD, Kim K, Burkholder JM, Colwell RR and others (1999) Emerging marine diseases: climate links and anthropogenic factors. Science 285:1505-1510

Hess GR, Randolph SE, Arneberg P, Chemini C and others (2001) Spatial aspects of disease dynamics. In: Hudson PJ, Rizzoli A, Grenfell BT, Heesterbeek H, Dobson AP (eds) The ecology of wildlife diseases. Oxford University Press, Oxford, p 102-118

Hines A, Oladirana GS, Bignell JP, Stentiford GD, Viant MR (2007) Direct sampling of organisms from the field and knowledge of their phenotype: key recommendations for environmental metabolomics. Environ Sci Technol 41: 3375-3381

Holt R, Boulinier T (2005) Ecosystems and parasitism: the spatial dimension. In: Thomas F, Renaud F, Guégan JF (eds) Parasitism and ecosystems. Oxford University Press, Oxford, p 68-84

ICES (International Council for the Exploration of the Seas) (2007) Report of the Working Group on Pathology and Diseases of Marine Organisms (WGPDMO). ICES Document CM 2007/MCC: 04. Available at www.ices.dk/iceswork/ wgdetail.asp? $\mathrm{wg}=$ WGPDMO

Klimpel S, Rückert S (2005) Life cycle strategy of Hysterothylacium aduncum to become the most abundant anisakid fish nematode in the North Sea. Parasitol Res 97:141-149

- Koehler A (2004) The gender-specific risk to liver toxicity and cancer of flounder (Platichthys flesus (L.)) at the German Wadden Sea coast. Aquat Toxicol 70:257-276

> Koehler A (1990) Identification of contaminant-induced cellular and subcellular lesions in the liver of flounder (Platichthys flesus L.) caught at differently polluted estuaries. Aquat Toxicol 16:271-294

$>$ Lafferty KD, Porter JW, Ford SE (2004) Are diseases increasing in the ocean? Annu Rev Ecol Evol Syst 35:31-54

Lang T, Dethlefsen V (1996) Fish disease monitoring: A valuable tool for pollution assessment? ICES CM 1996/E 17, ICES, Copenhagen

> Lyons BP, Stentiford GD, Green M, Bignell J and others (2004) DNA adduct analysis and histopathological biomarkers in European flounder (Platichthys flesus) sampled from UK estuaries. Mutat Res 552:177-186

> Lyons BP, Stentiford GD, Bignell J, Goodsir F and others (2006) A biological effects monitoring survey of Cardigan bay using flatfish histopathology, cellular biomarkers and sediment bioassays: findings of the Prince Madog prize 2003. Mar Environ Res 62:S342-S346

> McCallum HI, Harvell CD, Dobson A (2003) Rates of spread of marine pathogens. Ecol Lett 6:1062-1067 
McCallum HI, Kuris A, Harvell CD, Lafferty KD, Smith GW, Porter J (2004) Does terrestrial epidemiology apply to marine systems? Trends Ecol Evol 19:585-591

Myers MS, Rhodes LD, McCain BB (1987) Pathological anatomy and patterns of occurrence of hepatic neoplasms, putative preneoplastic lesions, and other idiopathic hepatic conditions in English sole (Parophrys vetulus) from Puget Sound, Washington. J Natl Cancer Inst 78: 333-363

Myers MS, Landahl JT, Krahn MM, Johnson LL, McCain BB (1990) Overview of studies on liver carcinogenesis in English sole from Puget Sound: evidence for a xenobiotic chemical etiology. I. Pathology and epizootiology. Sci Total Environ 94:33-50

Myers MS, Landahl JT, Krahn MM, McCain BB (1991) Relationship between hepatic neoplasms and related lesions and exposure to toxic chemicals in marine fish from the US West Coast. Environ Health Perspect 90:7-15

Myers MS, Olson OP, Johnson LL, Stehr CS, Hom T, Varanasi U (1992) Hepatic lesions other than neoplasms in subadult flatfish from Puget Sound, Washington; relationships with indices of contaminant exposure. Mar Environ Res 34:45-51

> Myers MS, Stehr CM, Olson OP, Johnson LL, McCain BB, Chan SL, Varanasi U (1994) Relationships between toxicopathic lesions and exposure to chemical contaminants in English sole (Parophrys vetulus), starry flounder (Pleuronectes stellatus), and white croaker (Genyonemus linatus) from selected marine sites on the Pacific Coast, USA. Environ Health Perspect 102:200-215

Myers MS, Johnson LL, Hom T, Collier TK, Stein JE, Varanasi U (1998) Toxicopathic lesions in subadult English sole (Pleuronectes vetulus) from Puget Sound, Washington, USA: relationships with other biomarkers of contaminant exposure. Mar Environ Res 45:47-67

Myers MS, Anulacion BF, French BL, Reichert WL and others (2008) Improved flatfish health following remediation of a PAH-contaminated site in Eagle Harbor, Washington. Aquat Toxicol 88:277-288

OSPAR (Oslo and Paris Commission) (1998a) JAMP guidelines for general biological effects monitoring. OSPAR agreement 2008-9, Oslo and Paris Commission, London

OSPAR (Oslo and Paris Commission) (1998b) JAMP guidelines for contaminant-specific biological effects monitoring. OSPAR agreement 1997-7, OSPAR Commission, London

OSPAR (Oslo and Paris Commission) (2000) Quality Status Report 2000 for the North-East Atlantic. OSPAR Commission, London

Ostfeld RS, Glass GE, Keesing F (2005) Spatial epidemiology: an emerging (or re-emerging) discipline. Trends Ecol Evol 20:328-336

Reichert WL, Myers MS, Peck-Miller K, French B and others (1998) Molecular epizootiology of genotoxic events in marine fish: linking contaminant exposure, DNA damage, and tissue-level alterations. Mutat Res 411:215-225

Rijnsdorp AD, Vethaak AD, van Leeuwen PI (1992) Population biology of dab Limanda limanda in the southeastern North Sea. Mar Ecol Prog Ser 91:19-35

Schiewe MH, Weber DD, Myers MS, Jacques FJ and others (1991) Induction of foci of cellular alteration and other

Editorial responsibility: Otto Kinne,

Oldendorf/Luhe, Germany hepatic lesions in English sole (Parophrys vetulus) exposed to an extract of an urban marine sediment. Can J Fish Aquat Sci 48:1750-1760

Stein JE, Reichert WL, Nishimito M, Varanasi U (1990) Overview of studies on liver carcinogenesis in English sole from Puget Sound; evidence for a xenobiotic chemical etiology II: biochemical studies. Sci Total Environ 94:51-69

Stentiford GD, Feist SW (2005) First case of intersex (ovotestis) in the flatfish species, dab (Limanda limanda): Dogger Bank, North Sea. Mar Ecol Prog Ser 301:307-310

Stentiford GD, Shields JD (2005) A review of the parasitic dinoflagellates Hematodinium species and Hematodiniumlike infections in marine crustaceans. Dis Aquat Org 66: $47-70$

Stentiford GD, Longshaw M, Lyons BP, Jones G, Green M, Feist SW (2003) Histopathological biomarkers in estuarine fish species for the assessment of biological effects of contaminants. Mar Environ Res 55:137-159

Stentiford GD, Johnson PJ, Martin A, Wenbin W and others (2005) Liver tumours in wild flatfish: a histopathological, proteomic and metabolomic study. OMICS J Integr Biol 9: 281-299

Thain JE, Miller B, Service M (2006) Monitoring the quality of the marine environment, 2003-2004. Sci Ser Aquat Environ Monit Rep no. 58, Cefas Lowestoft

Thain JE, Vethaak AD, Hylland K (2008) Contaminants in marine ecosystems: developing an integrated indicator framework using biological effects techniques. ICES J Mar Sci 65:1508-1514

Tysklind N, Taylor MI, Lyons BP, McCarthy ID, Carvalho GR (in press) Development of 30 microsatellite markers for dab (Limanda limanda L.): a key UK marine biomonitoring species. Mol Ecol Resour doi: 10.1111/j.1755-0998. 2008.02513. $\mathrm{x}$

Vethaak AD, Wester PW (1996) Diseases of flounder Platichthys flesus in Dutch coastal and estuarine waters, with particular reference to environmental stress factors. II. Liver histopathology. Dis Aquat Org 26:99-116

Vethaak AD, Jol JG, Meijboom A, Eggens ML and others (1996) Skin and liver diseases induced in flounder (Platichthys flesus) after long-term exposure to contaminated sediments in large scale mesocosms. Environ Health Perspect 104:1218-1229

Viarengo A, Lowe D, Bolognesi C, Fabbri E, Koehler A (2007) The use of biomarkers in biomonitoring: a 2-tier approach assessing the level of pollutant induced stress syndrome in sentinel organisms. Comp Biochem Physiol C Toxicol Pharmacol 146:281-300

Ward JR, Lafferty KD (2004) The elusive baseline of marine disease: Are diseases in ocean ecosystems increasing? PLoS Biol 2:542-547

> Ward DG, Wei W, Cheng Y, Billingham LJ and others (2006) Plasma proteome analysis reveals the geographical origin and liver tumor status of dab (Limanda limanda) from UK marine waters. Environ Sci Technol 40:4031-4036

Wosniok W, Lang T, Dethlefsen V, Feist SW, McVicar AH, Mellergaard S, Vethaak AD (2000) Analysis of ICES longterm data on diseases of North Sea dab (Limanda limanda) in relation to contaminants and other environmental factors. ICES CM 2000/S:12, ICES, Copenhagen

Submitted: November 28, 2008; Accepted: January 27, 2009 Proofs received from author(s): March 31, 2009 